\title{
Traditional Dances as a Means of Teaching Social Skills to Elementary School Students
}

\author{
Grigorios Masadis \\ Department of Physical Education and Sport Science/Democritus University of Thrace, \\ Greece, gregmas1971@gmail.com.
}

\section{Filippos Filippou}

Assoc.Prof.,Physical Education \& Sport Science,DUTh, Greece, ffilippo@phyed.duth.gr

\section{Vasiliki Derri}

Prof., Physical Education \& Sport Science, DUTh, Greece, vaderri@phyed.duth.gr

\section{Georgios Mavridis}

Asst. Prof., Physical Education \& Sport Science, DUTh, Greece, mageorge@otenet.gr

\section{Stella Rokka}

Assoc.Prof.,Physical Education \& Sport Science,DUTh, Greece, srokka@phyed.duth.gr

The aim of this study was to investigate: a. the effect of an interdisciplinary program of Greek traditional dance by the means of the teamwork method of teaching social skills to students. b. whether this effect was similar for boys and girls. The sample of the study constituted of 206 elementary school pupils (4th, 5 th, and 6th class). The intervention program lasted for two months. There were a total of sixteen lessons ( 2 per week) which concerned the acquisition of social skills through Greek traditional dance (the experimental group). The method in use was either the group divided work or teamwork. The Greek version (Masadis et al., 2016) of Matson Evaluation of Social Skills with Youngsters (MESSY-II) (Matson et al., 2012) was applied to collect the research data. This in order to be analysed required the following statistical analysis: a. Descriptive statistics b. t-test for independent sample c. Reliability analysis (Cronbach's $\alpha$ ) and d. Repeated Measures ANOVA. The findings and the evaluation of the study suggest that the teamwork method is the most appropriate to adopt in social skills learning for the last 3 grades of primary school and traditional dancing the best choice to make.

Keywords: dance, teaching methods, socialization, cooperation, social skills 


\section{INTRODUCTION}

The rapid changes in society as a result of globalization - a large scale human migration, scientific and technological progress - have an impact on the education system which ought to align itself with the fast moving world (Konstantinou, 2005). Students, in particular, face new challenges and if they are to succeed it is essential that they develop communication skills and an ability to adjust to contemporary teaching and working environments. This in turn, will ease their integration into the modern world (Papaioannou et al., 2003). In bibliography such abilities are also known as life skills, very often a ticket to stardom (Danish \& Nellen, 1997). According to UNICEF (2003) life skills are a total of social, cognitive and emotional separate subs kills.

Social skills hold a dominant position among the others as they open channels of communication and support the expression of opinion and emotions so that individuals will be able to navigate themselves into groups (Brooks, 1984). Gresham and Eliot (1990) point out that social skills are established when a person demonstrates socially acceptable behavior thus interacting efficiently with others and refraining from negative and antisocial activities. Riggio (1986) supports that all the fundamental social skills develop into social abilities and strategies, that shouldn't be treated as an entirety but as a total consisted of various essential subcategories. This is not a linear relationship and therefore the final total of it cannot render one socially acceptable and useful. Social skills learning requires balanced development and most importantly classification, according to Riggio (1986).

Family, school and different social groups are the pillars of social skills learning, with the family environment being the first step of a child's social education (Brooks, 1984). According to Simons, Whitbeck and Conger (1991) the parental upbringing plays a vital role in social skills' improvement and is a shield against lawbreaking. Family promotes social skills in the early stages and later school completes and reinforces social learning. Sergin et al. (2007) claim that close relationships between teachers and students facilitates skills' acquisition, reduces stress and depression, which is often the result of social isolation. Juvenile delinquency is very common at school and social skills have significantly contributed to tackle the issue since students learn to get along with each other, work together take responsibilities, control their own behavior and improve their school performance (Eliot \& Gresham, 1991; Van Vugt et al., 2013).

School subjects give teenagers the opportunity to learn social skills. And, among these subjects, PE is arguably the most important because of its nature to keep students physically close and interact with each other. Children participate enthusiastically in games and activities and teachers know this result in more effective learning (Eldar \& Ayvazo, 2009). PE teaches rules and behavior, respect for others, how to deal with a win or a defeat and generally how to adopt positive social manners (Biddle et al., 2003). In addition, provided the school environment is relaxing and the syllabus appropriate and supportive of social skills, students develop team spirit; they learn how to cooperate and help one another, exchange ideas and solve problems individually and in groups (Gregoriadis et al., 2013).

Primary and secondary school education are crucial in social skills learning. Well planned sports activities at schools promote physical and mental health (Lv \&Takami, 
2015; Magotsiou \& Goudas, 2007) confirmed with their research the significance of PE in the development of social skills thus reducing class disruption and irritability. The researchers also point out the contribution of the cooperative teaching method to social values which are inextricable connected with PE.

Among the sports activities of the Greek National Curriculum in both primary and secondary education are traditional dances (Diggelidis et al., 2007). According to Bilmann (1998) dancing is the delight of one's faculties. Dancers savour the harmony, speed, agility and reflections of movements. Dancing, by nature a physical and mental activity, breathes new life into those involved. And Greek traditional dances -whose main features are the circle and group movements don't fall short of the above qualities. The healing powers of group dancing have been known since the ancient times when people used it to deal with negative emotions and feelings, such as anger, pain and stress. Traditional dancing is circular and strengthens ties among dancers. As an individual the person develops the feeling of fitting in with the others and gradually the dancer expresses strong emotions, well hidden in his inner self (Spenser, 1985). Traditional dancing guarantees social skills' establishment. Lack of them might lead to isolation and depression. Teaching social skills to children as a therapeutic method is considered, by and large, positive (Segrin, 2000). In Koshland et al. (2004) studies, dancing was successfully used to confront school violence and aggressiveness, to enhance emotions and internal motivation and finally to raise students' sense of selfesteem. Moreover, taking part in dancing activities helps with handling social and emotional issues (Karkou et al., 2010; Mala et al., 2012). Traditional dances, as part of the National Curriculum, aim at the development of students' physical, mental and emotional wellbeing. Therefore, instilling these skills secures students' progress and improvement in many aspects (Diggelidis et al., 2007).

From the above, it can be inferred that studies related to social skills learning through traditional dancing with the team-cooperative method in the last three grades of primary school do not exist. Consequently, the aim of this study was to investigate: a. the effect of an interdisciplinary program of Greek folk dance, by the means of the teamcooperative method in teaching social skills to $4^{\text {th }}, 5^{\text {th }}$, and $6^{\text {th }}$ primary school graders. $b$. Whether this effect was similar for boys and girls.

\section{METHOD}

\section{Design of the Study}

The intervention program lasted for eight (8) weeks. In total, the experimental group attended 16 lessons ( 2 per week), concerning the development of social skills through Greek traditional dance. The method used was that of group assignment or team working. The participants were divided into heterogeneous four-member groups of mixed performance and gender (Kanakis, 2001). During the program, the PE teacher played a supervising and encouraging role, eager to resolve any issue, should it occur, and giving assignments such as the collection of information on a dance such as Kalamatianos (where it was danced, social characteristics of the era, famous Kalamatianos songs etc.). After the demonstration of some new steps by a skillful local dancer, a member of each group is assigned to help the rest of the members improve 
their performance. By the fourth lesson, each pair of groups was united into one and in the last two lessons the whole experimental group was united in one team, according to the teaching method suggested by Kanakis (2011). The result was the general improvement of the majority of the participants. During the process, the students were also encouraged to draw pictures inspired by the dance they were taught.

The control group was taught the same dance at the same period along with the experimental group. However, the method that was applied was teacher-oriented which adopted the order style (Serbezis, 2012) since it underlined only the kinetic form of dance. Similar dances were chosen from the Greek National Curriculum and the local group's repertoire namely Kalamatianos, Tsamikos, Enteka, Zonaradikos, Syrtos and Marmarenia mou vrysoula (the last two are local dances).

\section{Sample}

The sample of the study constituted of 206 elementary school pupils $\left(4^{\text {th }}, 5^{\text {th }}\right.$, and $6^{\text {th }}$ class). There were divided into two groups, the experimental ( $\mathrm{n}=132,66$ male and 66 female pupils), who participated in an intervention program (teaching social skills through Greek traditional dances based on the cooperative method) for a period of eight weeks and the control ( $\mathrm{n}=74,43$ male and 31 female pupils), who were taught the traditional dances in an order like manner. The choice of the pupils of two groups was made by means of random sampling (table 1 ).

Table 1

Distribution of sample per gender and class attendance

\begin{tabular}{llllllllrr}
\hline $\begin{array}{l}\text { lass } \\
\text { attendance }\end{array}$ & \multicolumn{2}{l}{ Experimental group } & \multicolumn{7}{c}{ Control group } \\
\hline & Male & \multicolumn{3}{l}{ Female } & Male & \multicolumn{3}{c}{ Female } & Total \\
\hline $4^{\text {th }}(10$ years & 20 & $9.71 \%$ & 28 & $13.59 \%$ & 14 & $6.80 \%$ & 14 & $6.80 \%$ & 76 \\
\hline $5^{\text {th }}(11$ years $)$ & 26 & $12.62 \%$ & 13 & $6.31 \%$ & 17 & $8.25 \%$ & 10 & $4.84 \%$ & 66 \\
\hline $5^{\text {th }}(11$ years $)$ & 20 & $9.71 \%$ & 25 & $12.14 \%$ & 12 & $5.83 \%$ & 7 & $3.40 \%$ & 64 \\
Total & 66 & $32.04 \%$ & 66 & $32.04 \%$ & 43 & $20.88 \%$ & 31 & $15.04 \%$ & 206 \\
\hline
\end{tabular}

\section{Instrument}

The Greek version (Masadis et al., 2016) of Matson Evaluation of Social Skills with Youngsters (MESSY-II) (Matson et al., 2012) was employed in order to gather data for the study. The questionnaire is made up of 57 questions/statements based on three factors that examine the three aspects of social skills: the first which is called "Hostile" consists of twenty seven (27) questions, for example "Is jealous of other people". The second, "Adaptive/Appropriate" contains nineteen (19) questions, such as "Says thank you" and is happy when someone does something for him/her" and the third aspect is called "Inappropriately Assertive/Overconfident" including eleven (11) questions, namely "Always wants to be first".

The answers were given in a five-point Likert type scale ranging from $1=$ totally disagree to 5=totally agree. Both the general and the partial (for each individual factor) evaluation of social skills were of negative direction. That is why there was not a reversal of answers for the variants composing the factor Adaptive/Appropriate, except for the questions $4,9,13,16,19$ which were reversed in order to have the same negative 
direction. High grading (both partial and general) shows a low level of social skills, while low grading shows a good/acceptable level of social skills.

\section{Data collection}

Parents were requested to give written permission to allow their children to participate the programme after having been briefed on the aim of the research and receiving the assurance that the results of the study will be strictly used only for educational and scientific purposes. For the assessment of the intervention program the questionnaires were completed by PE teachers at the initial $\left(1^{\text {st }}\right.$ lesson $)$ and the final measurements $\left(16^{\text {th }}\right.$ lessons).

\section{Statistical analysis}

For the statistical analysis of the data the following methods were used: Descriptive statistics, Independent Sample t-test, Reliability analysis for the search of internal cohesion of the factors and Repeated measures Anova analysis for the examination of possible deficits of different measurements within the team or out of it and any differences of the mean between the experimental and control group and also the gender.

\section{FINDINGS}

At the beginning, three independent sample tests were held to find out if there were statistically significant differences between the experimental and the control group at the initial measurement. Results showed that there were not statistically significant differences in any of the three factors. Therefore, the members of the two groups were considered to be characterized by the same level to the factors which were studied before the intervention program (table 2).

Table 2

Means and T-test at the initial measurement

\begin{tabular}{llllllc}
\hline & Factors & Experimental & Control & $\mathrm{t}$ & $\mathrm{df}$ & $\mathrm{p}$ \\
\hline 1 & Hostile & 3.3342 & 3.4404 & -.511 & 204 & $>.05$ \\
\hline 2 & Appropriate & 3.6009 & 3.6451 & -.276 & 204 & $>.05$ \\
\hline 3 & Inappropriately Assertive & 3.1563 & 3.1167 & .620 & 204 & $>.05$ \\
\hline
\end{tabular}

\section{Reliability analysis}

A reliability analysis was performed in order to examine the internal consistency, and therefore the reliability of the items constituting the three factors under study both in the pre- and post-test measurement. The reliability test was based on the calculation of Cronbach's alpha. The results revealed that the factors had a satisfactory reliability score (a>.60) (Table 3).

Table 3

Reliability analysis of the three factors, at the initial and final measurements three factors

\begin{tabular}{lcc}
\hline Factors & \multicolumn{2}{c}{ Cronbach's a } \\
& Initial measure & Final measure \\
Hostile & .92 & .93 \\
Appropriate & .91 & .92 \\
Inappropriately Assertive & .94 & .94 \\
\hline
\end{tabular}




\section{Repeated Measures ANOVA analysis}

The Repeated measures Anova analysis was applied for the "hostile" factor. The analysis model (2X2) included the variable "measurement" (initial - final) as the repetition variable and the variable "group" (experimental - control) as the independent variable. The results showed that there was a statistically significant interaction between the variable "measurement" and "group" for the hostile social skills $\left[F_{(1,204)}=214.85\right.$, $\mathrm{p}<.001]$. The interaction analysis, with the use of the multiple comparison test (Post Hoc Bonferroni), showed that the experimental group had a statistically significant improvement (decreased in grades) after the end of the intervention program, while the control group did not show any statistically important difference (table 4).

As concerns the effect of the program one can highlight the following: a) the male students of the experimental group had a steady development after every single measurement $\left(\mathrm{F}_{(1,132)}=333.04, \mathrm{p}<.05\right.$, initial measurement $\mathrm{M}=3.37$ \& $\mathrm{SD}=1.46$, final measurement $\mathrm{M}=2.02 \& \mathrm{SD}=.77$ ), decreasing hostile social skills, while the control group did not have any statistically important differentiation $\left(\mathrm{F}_{(1,132)}=.010, \mathrm{p}>.05\right.$, initial measurement $\mathrm{M}=3.54 \& \mathrm{SD}=1.41$, final measurement $\mathrm{M}=3.53 \& \mathrm{SD}=1.40$ ), and $\mathrm{b}$ ) female students of the experimental group presented an important differentiation after every single measurement $\left(\mathrm{F}_{(1,95)}=92.95, \mathrm{p}<.05\right.$, initial measurement $\mathrm{M}=3.30$ \& $\mathrm{SD}=1.42$, final measurement $\mathrm{M}=1.92 \& \mathrm{SD}=.72$ ) decreasing hostile social skills. The female students of the control group did not present a statistically important difference $\left(\mathrm{F}_{(1,95)}=.025, \mathrm{p}>.05\right.$, initial measurement $\mathrm{M}=3.30 \& \mathrm{SD}=1.45$, final measurement $\mathrm{M}=3.24 \& \mathrm{SD}=1.42)$.

Table 4

Means (M), Standard Deviations (SD), Significant Differences (F) of the experimental and control group at the initial and final measurement

\begin{tabular}{|c|c|c|c|c|c|c|}
\hline \multirow{2}{*}{ Factors } & \multirow{2}{*}{ Group } & \multicolumn{2}{|c|}{ Initial } & \multicolumn{2}{|c|}{ Final } & \multirow{2}{*}{$\begin{array}{l}\text { Measurement/Group } \\
\text { Interaction }\end{array}$} \\
\hline & & $\mathrm{M}$ & S.D & $\mathrm{M}$ & S.D & \\
\hline \multirow[t]{2}{*}{ Hostile } & Experimental & 3.33 & 1.44 & 1.97 & .75 & \multirow{2}{*}{$\mathrm{F}_{(1,204)}=214.85, \mathrm{p}<.001$} \\
\hline & Control & 3.44 & 1.42 & 3.41 & 1.41 & \\
\hline \multirow[t]{2}{*}{ Appropriate } & Experimental & 3.60 & 1.09 & 1.92 & .61 & \multirow{2}{*}{$\mathrm{F}_{(1,204)}=526.44, \mathrm{p}<.001$} \\
\hline & Control & 3.65 & 1.12 & 3.62 & 1.13 & \\
\hline \multirow{2}{*}{$\begin{array}{l}\text { Inappropriately } \\
\text { Assertive }\end{array}$} & Experimental & 3.16 & .68 & 1.60 & .46 & \multirow{2}{*}{$\mathrm{F}_{(1,204)}=560.48, \mathrm{p}<.001$} \\
\hline & Control & 3.12 & .61 & 3.12 & .67 & \\
\hline
\end{tabular}

The Repeated measures Anova analysis was applied for the "appropriate" factor. The analysis model (2X2) included the variable "measurement" (initial - final) as the repetition variable and the variable "group" (experimental - control) as the independent variable. The results showed that there was a statistically significant interaction between the variable "measurement" and "group" for the appropriate social skills $\left[F_{(1,204)}\right.$ $=526.44, p<.001]$. The interaction analysis, with the use of the multiple comparison test (Post Hoc Bonferroni), showed that the experimental group had a statistically significant improvement (shown in negative grades) after the end of the intervention program, while the control group did not show any statistically important difference (table 4).

As concerns the effect of the program one can highlight the following: a) the male students of the experimental group had a steady development after every single measurement $\left(\mathrm{F}_{(1,107)}=342.89, \mathrm{p}<.001\right.$, initial measurement $\mathrm{M}=3.74 \& \mathrm{SD}=1.08$, final 
measurement $\mathrm{M}=1.96$ \& $\mathrm{SD}=.61)$, increasing appropriate social skills, while the control group did not have any statistically important differentiation $\left(\mathrm{F}_{(1,107)}=.010, \mathrm{p}>.05\right.$, initial measurement $\mathrm{M}=3.81 \& \mathrm{SD}=1.04$, final measurement $\mathrm{M}=3.79 \& \mathrm{SD}=1.07$ ), and $\mathrm{b}$ ) female students of the experimental group presented an important differentiation after every single measurement $\left(\mathrm{F}_{(1,95)}=198.44, \mathrm{p}<.05\right.$, initial measurement $\mathrm{M}=3.47$ \& $\mathrm{SD}=1.09$, final measurement $\mathrm{M}=1.90 \& \mathrm{SD}=.61$ ) increasing appropriate social skills (shown in negative grades). The female students of the control group did not present a statistically important difference $\left(\mathrm{F}_{(1,95)}=.017, \mathrm{p}>.05\right.$, initial measurement $\mathrm{M}=3.41$ \& $\mathrm{SD}=1.21$, final measurement $\mathrm{M}=3.37 \& \mathrm{SD}=1.19$ ).

The Repeated measures Anova analysis was applied for the "inappropriate assertive" factor. The analysis model (2X2) included the variable "measurement" (initial - final) as the repetition variable and the variable "group" (experimental - control) as the independent variable. The results showed that there was a statistically significant interaction between the variable "measurement" and "group" for the inappropriate assertive social skills $\left[\mathrm{F}_{(1,204)}=560.48, \mathrm{p}<.001\right]$. The interaction analysis, with the use of the multiple comparison test (Post Hoc Bonferroni), showed that the experimental group had a statistically significant improvement (decreased in grades) after the end of the intervention program, while the control group did not show any statistically important difference (table 4).

As concerns the effect of the program one can highlight the following: a) the students of the experimental group had a steady development after every single measurement $\left(\mathrm{F}_{(1,107)}=309.37, \mathrm{p}<.001\right.$, initial measurement $\mathrm{M}=3.16 \& \mathrm{SD}=.68$, final measurement $\mathrm{M}=1.60 \& \mathrm{SD}=.46)$, decreasing inappropriate assertive social skills, while the control group did not have any statistically important differentiation $\left(\mathrm{F}_{(1,107)}=.010, \mathrm{p}>.05\right.$, initial measurement $\mathrm{M}=3.18$ \& $\mathrm{SD}=.61$, final measurement $\mathrm{M}=3.12 \& \mathrm{SD}=.67$ ), b) female students of the experimental group presented an important differentiation after every single measurement $\left(\mathrm{F}_{(1,95)}=242.11, \mathrm{p}<.001\right.$, initial measurement $\mathrm{M}=3.17$ \& $\mathrm{SD}=.64$, final measurement $\mathrm{M}=1.60 \& \mathrm{SD}=.46$ ) decreasing inappropriate social skills. The female students of the control group did not present a statistically important difference $\left(\mathrm{F}_{(1,95)}=.007, \mathrm{p}>.05\right.$, initial measurement $\mathrm{M}=3.03 \& \mathrm{SD}=.74$, final measurement $\mathrm{M}=3.05 \& \mathrm{SD}=.75)$.

\section{DISCUSSION}

The aim of this study was to investigate the effect of an interdisciplinary program of Greek traditional dance, through the team-cooperative method in teaching social skills to $4^{\text {th }}, 5$ th and $6^{\text {th }}$ graders of primary school and whether this effect was similar for boys and girls. The findings suggest that the scheme of social skills learning based on the Greek dancing teaching project - with the use of the team-cooperative method-was effective as there was significant decrease in inappropriate and aggressive social behavior and, on the other hand, dramatic rise in socially acceptable manners of the experimental group. Conversely, the control group members didn't display any noticeable departure of previous demeanour. In addition, the repeated measurements of the study demonstrate that the intervention program affected equally both sexes of the experimental group. Yet, no changes were recorded in the control team or within the grades of the control group. 
The results of the present survey go along with those in the past (Buss et al., 1980), according to which, a well-structured program of kinetic skills contributes substantially to the reduction of undesirable behavior, such as aggressiveness, selfishness and distraction. However, this study is in contrast with the research of Malinauskas (2008), Emeljanovas (2013), and Margetts (2005) as female students appear to possess higher levels of social skills compared to males. This might be put down to the different group ages -the current study took samples aged 10 to 12 years whereas the others were from 14 to 17 years old.

The determining factor that altered the behavior of the control group was the cooperative method of teaching the traditional dances since it was the experimental team only that produced such remarkable changes. It proves that the groups founded for the programme worked efficiently and the smooth operation of the teams was essential for the cooperative method and the project too. This means that throughout the lessons there was a lively and friendly environment among the students which contributed to open the channels of communication. Fortunately, there was no place for competitiveness and individualism, two elements that poison the today's school and society (Kakana, 2008; Kazela, 2009; Matsagouras, 2008). The group deepened their understanding of one another and come to the realisation of togetherness and interdependence. As a consequence, it became clear that the achievement of individual's goals in a group is the outcome of collective aims which in turn rely on the contribution of each team member. All the above added to the development of good communication between the members, acceptance of the different and the opposing view but mainly the value of cooperation and mutual support.

\section{CONCLUSION}

From the survey's findings it can be drawn that the cooperative method of teaching Greek dances is the most appropriate for social skills learning regarding the students of the three last grades of primary school and also that Greek traditional dances are the ultimate means to achieve this objective.

\section{SUGGESTIONS FOR PRACTICAL APPLICATIONS}

As it was stated previous, the age of 10-11 and 12 are the formative years in one's life since it is mainly during this period that students' social aspects of their personality are built and develop and later smoothly integrate into adults' society. Therefore it is essential if not imperative that $\mathrm{PE}$ as a school subject incorporates among others social skills learning through kinetic activities supported by different teaching methods. Among them Greek traditional dances hold a dominant position, and are inseparable components of the PE curriculum, as this study has proved. If taught efficiently and with the assistance of the cooperative method, Greek traditional dances could function as the springboard of social skills. For this to happen, PE educators should be aware of the different levels of social skills that students can reach.

Therefore it is recommended that PE teachers of primary schools make the best of the specific questionnaire, which was used in this research, in order to evaluate the social skills' integration of their students. They are also advised to demonstrate social skills through Greek traditional dances with the cooperative method. 


\section{REFERENCES}

Biddle, S., Wang, C.J., Kavussanu, M., \& Spray, C. (2003). Correlates of achievement goal orientations in physical activity: A systematic review of research. European Journal of Sport Science, 3(5), 1-20.https://doi.org/10.1080/17461390300073504

Billmann, F.S. (1998). When dances have therapeutic qualities. Athens. Greek Literature Publications.

Brooks, K. (1984). Life-skills taxonomy: Defining elements of effective functioning through the use of the Delphi technique. (Unpublished doctoral dissertation). Georgia: University of Georgia.

Danisch, S.J., \& Nellen, V.C. (1997). New roles for sport psychologists: Teaching life skills through sport to at-risk youth. Quest, 49(1), 100-113. https://doi.org /10.1080/00336297.1997.10484226

Diggelidis, N., Theodorakis, I., Zetou, E., \& Demas, I. (2007). Physical Education $5^{\text {th }}$ and $6^{\text {th }}$ grade of Elementary school. Teacher's guide. Athens, textbooks Publishing Organisation.

Eldar, E., \& Ayvazo, S. (2009). Educating through the physical-rationale. Education and Treatment of Children, 32(3), 471-486. https://doi.org/10. 1080/ 17408980701345741

Elliott, S.N., \& Gresham, F.M. (1991).Social skills intervention guide. Circle Pines, MN: American Guidance Service.

Gresham, F.M., \& Elliott, S.N. (1990). Social skills rating system: Manual American Guidance Service.

Gregoriadis, A., Grammatikopoulos, V., \& Zachopoulou, E. (2013). Evaluating preschoolers' social skills: The impact of a physical education program from the parents' perspective. International Journal of Humanities and Social Science, 3(10), 4051. http://hdl.handle.net/10149/596491

Kakana, D.M. (2008).Cooperative teaching and learning. Theoretical approaches and educational prospects. Thessaloniki. Kyriakides Bros plc.

Karkou, V., Fullarton, A., \& Scarth, S. (2010). Finding a Way Out of the Labyrinth through Dance Movement Psychotherapy: Collaborative Work in a Mental Health Promotion Programme for Secondary Schools. In: V. Karkou (ed): Arts Therapies in Schools: Research and Practice. (pp. 59-84). London. Jessica Kingsley.

Kanakis, I. (2001). Teaching - learning organization to work groups. Athens. Tipothito publications.

Kazela, K. (2009). Cooperative teaching and learning in pre-school education. Theory and practical applications. Athens. Odysseus publications.

Konstantinou, A. (2005). How effectively manage your school. Nicosia: Kantzilaris.

Koshland, L., Wilson, J., \& Wittaker, B. (2004). PEACE through dance/movement: Evaluating a violence prevention program. American Journal of Dance Therapy, 26(2), 69-90. https://link.springer.com/article/10.1007/s10465-004-0786-z 
Lv, L., \& Takami, K. (2015). The relationship between social skills and sports activities among Chinese college students. Psychology, 6. 393-399. http://dx.doi.org /10.4236 /psych.2015.64036

Magotsiou, E., \& Goudas, M. (2007). Cooperative Learning as a Vehicle of Enhancing Social Skills in Physical Education. Inquiries in Sport \& Physical Education, 5(1), 8294. http://www.pe.uth.gr/hape/images/stories/emag/vol5_1/hape180.pdf

Mala, A., Karkou, V., \& Meekums, B. (2012). Dance/Movement therapy (D/MT) for depression: A scoping review. The Arts in Psychotherapy, 39(4), 287-295. https://doi.org/10.1016/j.aip.2012.04.002

Masadis, Gr., Filippou, F., Derri, V., \& Papaioannou, Ath. (2016). Reliability and validity of the Matson evaluation of social skills with youngsters (MESSY II) in Greek Context. Sport Science, 9(2), 92-96.

http://www.sposci.com/PDFS/BR0902/SVEE/04\%20CL\%2015\%20GM.pdf

Matsagouras E. (2008). Cooperative teaching and learning. Athens. Gregory.

Matson, J., Neal, D., Worley, J., Kozlowski, A., \& Fodstad, J. (2012). Factor structure of the Matson Evaluation of Social Skills with Youngsters-II (MESSY-II). Research in Developmental Disabilities, 33:2067-2071.

http://dx.doi.org/10.1016/j.ridd.2010.09.026

Papaioannou, A., Theodorakis, I., \& Goudas, M. (2003). Improving teaching in physical education. Thessaloniki: Christodoulidis publications.

Riggio, R.E. (1986). Assessment of basic social skills. Journal of Personality and Social Psychology, 51(3), 649-660.http://dx.doi.org/10.1037/0022-3514.51.3.649

Segrin, C., Hanzal, A., Donnerstein, C., Taylor, M., \& Domschke, T.J. (2007). Social Skills, psychological wellbeing, and the mediating role of perceived stress. Anxiety, Stress, and Coping, 20(3), 321-329. http://dx.doi.org/10.4236/psych.2015.64036

Serbezis, B. (2012). Method and teaching of dancing. Choice of teaching method. Unpublished manuscript, Department of Physical Education and Sport Science, Democritus University of Thrace, Komotini, Greece.

Simons, R.L., Whitbeck, L.B., Conger, R.D., \& Conger, K.J. (1991). Parenting factors, social skills, and value commitments as precursors to school failure, involvement with deviant peers, and delinquent behavior. Journal of Youth and Adolescence, 20(6), 645664. DOI: $10.1007 / \mathrm{BF} 01537367$

Segrin, C. (2000). Social skills deficits associated with depression. Clinical Psychology Review, 20(3), 379-403. https://doi.org/10.1016/S0272-7358(98)00104-4

Spencer, P. (1985). Society and the dance. Cambridge: Cambridge University Press.

Van Vugt, E., Deković, M., Prinzie, P., Stams, G., \& Asscher, J. (2013). Evaluation of a group-based social skills training for children with problem behavior. Children and Youth Services Review, 35(1), 162-167. DOI: 10.1016/j. child youth. 2012.09.022

*** Unisef (2003). How does life skills-based education contribute to Unisef's goal of quality education? Retrieved from www.unisef.org 